\title{
Liberdade de Escolha no Serviço Nacional de Saúde - o Caso do VIH
}

\author{
Freedom of Choice in the National Health Service - the Case of HIV
}

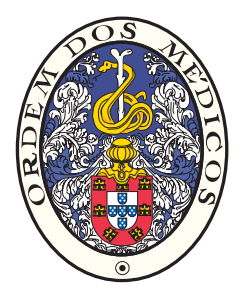

Julian PERELMAN 1

Acta Med Port 2015 Mar-Apr;28(2):138-140

Palavras-Chave: Direitos do Doente; Infecções por VIH/tratamento; Portugal; Serviço Nacional de Saúde; Tomada de Decisão.

Keywords: Patient Rights; HIV Infections/therapy; Portugal; National Health Programs; Decision Making.

A liberdade de escolha no Serviço Nacional de Saúde (SNS) é um tema que volta ao debate de forma recorrente, sob diferentes formas. A mais recente é o caso do tratamento do VIH. Doentes, apoiados por médicos especialistas e associações, reclamam a livre escolha do hospital, enfrentando por vezes as instituições do SNS. Valerá a pena reflectir sobre este debate, detalhando que o simples e óbvio - a liberdade do paciente escolher o seu médico - é na verdade complexo pelas suas possíveis consequências.

A liberdade de escolha pode ser uma componente do bem-estar do doente, e um elemento de qualidade do sistema de saúde, da sua responsiveness, para utilizar este muito explícito termo inglês que poderíamos traduzir por 'capacidade de resposta'. No caso do VIH, o pedido é perfeitamente compreensível. A doença é grave e incurável, e ainda por vezes (ou muitas vezes?) estigmatizante; o doente poderá ter uma esperança de vida próxima dos não doentes, mas estará em tratamento para a vida inteira. Daí a necessidade de uma relação de confiança, duradoura, com um médico especialista altamente competente, num local próximo do lugar de residência, num ambiente de empatia onde será garantida a confidencialidade.

Segundo a teoria económica, a liberdade de escolha é desejável porque promove eficiência e qualidade, através do mercado e da concorrência. Ao escolher, espera-se que os utentes premeiem os melhores prestadores, e penalizem os piores. A liberdade de escolha é assim o principal instrumento para criar concorrência entre prestadores, obrigando os menos eficientes a melhorar as suas práticas ou a desaparecer, por falta de utentes e de rendimento. Podemos pensar, por exemplo, que a reforma da rede hospitalar que tarda tanto em concretizar-se por causa das resistências várias, já estaria realizada há tempo se em vez de desenhar redes no papel se deixasse funcionar o mercado - e que os mais pequenos, menos eficientes e/ou menos competentes desapareçam naturalmente por 'falta de clientes'. Foram estes argumentos, de eficiência e qualidade, que levaram o Reino Unido e a Suécia, com Serviços Nacionais de Saúde, a optar pela liberdade de escolha, fomentando a concorrência entre hospitais. Porquê, então, recusar esta liberdade que potencialmente traz benefícios ao doente e ao sistema?

\section{Liberdade de escolha e equidade}

O Serviço Nacional de Saúde foi desenhado e orientado em função de um objectivo de equidade. O legislador considerou desde o início que não era justo que dois doentes com a mesma patologia sejam tratados de forma diferente por razões socioeconómicas, étnicas, ou de género, por exemplo. Ora, estudos realizados em países onde a liberdade de escolha existe demonstram que a maior parte dos utentes escolhe o prestador mais próximo, ou delegam a escolha no médico de família. ${ }^{1}$ Só não escolhem desta forma os que têm a possibilidade de escolher: os que têm mais dinheiro para deslocar-se longe da sua residência; os mais jovens, porque também têm maior facilidade para se deslocar; os mais educados, que recolhem informação sobre os prestadores e têm capacidade para compará-los; e sobretudo os que, possuindo estas características, tiveram más experiências no hospital próximo. ${ }^{2}$ A liberdade de escolha é um luxo, que aproveitam aqueles que, pelo seu capital económico, social e cultural, conseguem perceber o sistema de saúde, dialogar com os seus profissionais, e tomar decisões. ${ }^{3}$ Os idosos, os mais pobres, os menos educados não usufruem desta liberdade, da qual, mostrem os estudos, também não usufruem os utentes com doenças graves ou cujo tratamento é muito incerto. ${ }^{2}$

Os hospitais mais pequenos, periféricos, ficarão então com os doentes que não podem escolher, por falta de dinheiro ou de conhecimentos. O que acontecerá com estes doentes se o seu hospital de proximidade é obrigado a fechar por 'falta de clientes'? Ou mesmo se sobrevive, com uma clientela reduzida, menos experiência e meios reduzidos em recursos humanos e equipamentos, reencaminhados para os hospitais mais atractivos? Na ausência de outras intervenções, a liberdade de escolha poderá ser causa de uma maior polarização dos cuidados.

Para a liberdade de escolha não criar iniquidade, deverá haver uma intervenção forte do Estado para fomentar a possibilidade de escolha dos que não podem esco-

1. Escola Nacional de Saúde Pública. Universidade Nova de Lisboa. Lisboa. Portugal.

Recebido: 02 de Dezembro de 2014 - Aceite: 26 de Janeiro de 2015 | Copyright @ Ordem dos Médicos 2015 
Iher - com subsídios aos transportes, e forte divulgação de informação -, ou na manutenção de estruturas menos atractivas, com o seu consequente aumento de custos. No Reino Unido, talvez pelas limitações fortes na capacidade de escolher da maioria dos utentes e dos seus médicos de família, não surgiu o verdadeiro mercado esperado, mantendo 'doses de concorrência' baixas. Isso explicará a ausência de impacto em termos de equidade. ${ }^{4}$

\section{Liberdade de escolha e qualidade}

Um segundo problema prende-se com o impacto esperado na qualidade, e a verdadeira capacidade de escolha. Os utentes - os que podem - exercem a sua liberdade de escolha; mas em função de que critérios? Obviamente, serão os elementos visíveis de qualidade: proximidade, acesso, acolhimento, simpatia, tempos de espera. Mesmo quando relatórios comparativos existem sobre outcomes, estes são pouco relevantes nas escolhas dos utentes. ${ }^{1}$ Ora, nada garante que a qualidade visível reflicta a qualidade invisível, ou seja, as competências dos profissionais, a qualidade dos equipamentos e os ganhos em saúde. Assim, a falta de informação, ou a informação assimétrica, obriga mesmo os mais educados a basear as escolhas nas aparências, nas experiências passadas, nos relatos e opiniões dos familiares e amigos. ${ }^{1}$ Por isso, não é de todo óbvio que a concorrência funcione neste sector tal como gostaríamos, favorecendo os melhores e penalizando os piores, e promovendo a qualidade global do sistema. Num estudo de 2008, Propper e colegas demonstraram, para o Reino Unido, uma associação positiva entre mortalidade por enfarte agudo do miocárdio e nível de concorrência, e uma relação inversa entre concorrência e tempos de espera, levando os autores a concluir que 'os hospitais nos mercados concorrenciais reduziram a qualidade não mensurável e não observável para melhorar os tempos de espera observáveis e mensuráveis'. ${ }^{5}$ Outros estudos obtêm no entanto resultados diferentes, ${ }^{6}$ salientando as dúvidas quanto ao impacto verdadeiro da concorrência na qualidade; os que todos no entanto evidenciaram foi que no Reino Unido, pelas razões enunciadas previamente, a liberdade de escolha não criou forte concorrência, porque poucos utentes verdadeiramente aproveitaram a possibilidade de escolher. ${ }^{7}$

Noutros termos, para a liberdade de escolha ser um instrumento de qualidade, mais uma vez será necessária uma intervenção forte do Estado para garantir a qualidade dos cuidados através de mecanismos de controlo e acreditação, e para informar da forma transparente e visível sobre a qualidade os cidadãos chamados a escolher. Esta informação, para produzir os seus efeitos nas escolhas de todos os cidadãos, deverá ser amplamente divulgada e publicitada, facilmente acessível, clara e fácil de perceber, com indica-

\section{REFERÊNCIAS}

1. Victoor A, Delnoij DM, Friele RD, Rademakers JJ. Determinants of patient choice of healthcare providers: a scoping review. BMC Health Serv Res. 2012;12:272.

2. Fotaki M, Roland M, Boyd A, McDonald R, Scheaff R, Smith L. What dores de qualidade que todos considerem relevantes. Caso contrário, tal como o Reino Unido, a liberdade de escolha ficará pouco efectiva por ser apenas o privilégio de alguns.

\section{Antes da liberdade de escolha, decisões pragmáticas}

A liberdade de escolha pode representar uma mais-valia para os utentes e para o sistema, mas para tal é indispensável um contexto favorável de forte empenhamento e capacidade do Estado na recolha e divulgação de informação, nos controlos de qualidade, na manutenção de estruturas menos procuradas mas garantia de equidade, e, como no modelo inglês, entregando ao médico de família o papel de gestor do doente. Estaremos prontos para a liberdade de escolha? Estará o Estado português pronto para criar estas condições?

Enquanto estas questões não ficam resolvidas, preocupemo-nos de forma mais pragmática pelos doentes com $\mathrm{VIH}$. O pedido de escolha, neste caso, parece muito mais relacionado com alguma insatisfação ou receio com o hospital atribuído pelo sistema, do que motivado por um desejo de escolher. Importa portanto, e antes de ponderar a 'revolução da liberdade de escolha', reflectir sobre como ir ao encontro desta insatisfação.

Em conclusão, a resposta passa por diferentes caminhos. Importa assegurar, antes de mais, que o hospital da área de residência é mesmo aquele mais próximo de onde vive o utente. Trata-se de uma questão meramente administrativa que pode ser resolvida. Mais complexo, importa facilitar e simplificar o caminho da referenciação; asseguremos que os doentes detectados positivos podem ser encaminhados de forma imediata - um factor de sucesso crucial das terapias - para este hospital da área, independentemente da instituição que o diagnosticou (centro de saúde, Centros de Aconselhamento (CAD), Centros de Atendimento a Toxicodependentes (CAT), Checkpoint, Liga Portuguesa contra a síndroma imunodeficiência humana (SIDA), etc.), numa 'via verde' para os especialistas onde estes se encontrem. Finalmente, devem ser implementados mecanismos que propiciem estruturas fora das grandes cidades onde seja possível fazer o teste e ser reencaminhado, se positivo, com qualidade e confidencialidade. $E$ trabalhemos entretanto para que algum dia haja condições para a liberdade de escolha deixar de ser utópica.

\section{CONFLITOS DE INTERESSE}

O autor declara não ter quaisquer conflitos de interesse relativamente ao presente artigo.

\section{FONTES DE FINANCIAMENTO}

Este trabalho não recebeu nenhuma contribuição de subsídio ou bolsa. 
2010;32:898-913.

4. Cooper ZN, McGuire A, Jones S, Le Grand J. Equity, waiting times, and NHS reforms: retrospective study. BMJ. 2009;339.

5. Propper C, Burgess S, Gossage D. Competition and quality: Evidence from the NHS internal market 1991-9*. Econ J. 2008:118:138-70.

6. Cooper Z, Gibbons S, Jones S, McGuire A. Does hospital competition save lives? Evidence from the English NHS patient choice reforms* Econ J. 2011;121:F228-F60.

7. Cookson R, Laudicella M, Donni PL, Dusheiko M. Effects of the Blair/ Brown NHS reforms on socioeconomic equity in health care. J Health Serv Res Policy. 2012;17:S55-63. 


\section{Liberdade de Escolha no Serviço Nacional de Saúde - o Caso do VIH}

Acta Med Port 2015:28:138-140

Publicado pela Acta Médica Portuguesa, a Revista Científica da Ordem dos Médicos

Av. Almirante Gago Coutinho, 151

1749-084 Lisboa, Portugal.

Tel: +351218428 215

E-mail: submissao@actamedicaportuguesa.com

www.actamedicaportuguesa.com

ISSN:0870-399X | e-ISSN: 1646-0758

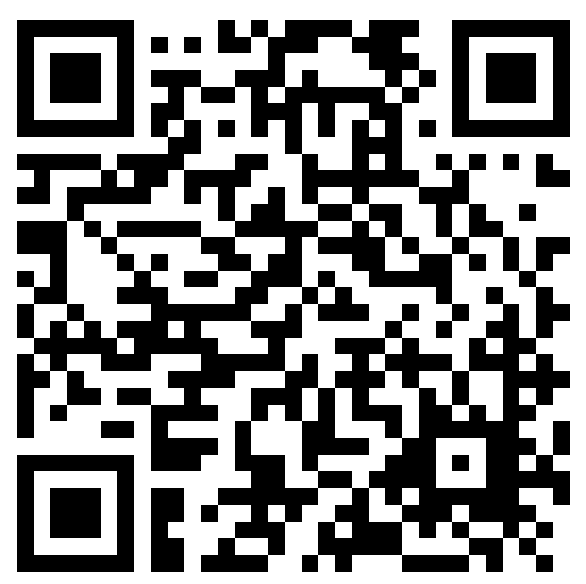

